\title{
Humility in Personality and Positive Psychology
}

Peter L. Samuelson, Ian M. Church

\section{\$1: Introduction}

Though "humble," might not be the first character trait to describe philosophers, a case could be made that the practice of philosophy demands a certain humility, or at least intellectual humility, requiring such traits as inquisitiveness, openness to new ideas, and a shared interest in pursuing truth. All of these traits are markers of intellectual humility, and, while the pursuit of the truth may involve the practice of humility simpliciter, we feel that a volume on the Philosophy of Humility would be best served by a better understanding of intellectual humility and, as such, this will be the focus of this chapter. ${ }^{1}$

Moreover, there are a few theoretical reasons for focusing on intellectual humility as opposed to humility more broadly. Of course, we typically and naturally (and reasonably!) assume that intellectual humility is a subset of humility; after all, it's easy to assume that if we are talking about intellectual humility then, we're talking about a specific kind of humility. But we might at least wonder if humility could be viably understood as a subset of intellectual humility; perhaps, for example, humility is just being intellectually humble about how someone conceives of themselves. If this is correct, then perhaps the most parsimonious way to understand humility is by way of intellectual humility. Indeed, in a seminal theoretical piece in the psychology literature, Tangney (2000) grounds the definition of humility in two realms: a proper understanding of the self (accurate assessment, keeping one's abilities/accomplishments in proper perspective, low self-focus) and a certain intellectual disposition (acknowledging mistakes, intellectual openness). Various measures of humility have also reflected these dimensions (Davis et al. 2011; Landrum 2011; Rowatt et al. 2006). The Honesty-humility dimension in the HEXACO, a trait assessment measure, assesses only accurate self-understanding (modesty, Ashton \& Lee 2008). Perhaps some of the problems that have been encountered in the measurement of humility could find resolution if humility was seen as a component of intellectual humility. But even if we fall understandably shy of this fairly radical proposal, a weaker thesis might nevertheless suit our purposes for this chapter: that our understanding of the philosophy of humility

\footnotetext{
${ }^{1}$ In addition, most of our work has been in the philosophy and science of intellectual humility, and, we feel that we have the most to contribute to this volume with a focus on that topic. See, for example, Church 2016, 2017; Samuelson and Church 2014; Samuelson et al. 2015; Church and Samuelson 2017; Church and Barrett 2017.
} 
could be significantly informed and developed by considering the emerging literature on intellectual humility.

We will begin with a discussion of intellectual humility as a character trait. The study of both humility and intellectual humility has been grounded in the methods and approach of personality psychology, specifically the examination of these virtues as traits. We will take a look at various wellknown traits in the personality psychology literature, discussing the "Big 5 " as they relate to intellectual humility, as well as other key traits related to cognition and the search for the truth. In this initial examination of intellectual humility as a trait, we use the terms "character trait" and "personality trait" interchangeably, though we recognize there is a case for making a distinction between the two (Miller 2014). We then examine the role of situations in the expression of intellectual humility, and for the interaction of "situation" and "trait." In the final analysis, it is the interaction of trait with situation that provides the most robust understanding of the psychology of any virtue, including humility and intellectual humility.

\section{\2: Intellectual humility as a Character Trait}

The recent interest in studying virtues and character has been inspired by the positive psychology movement but largely informed by the methods and approach of personality psychology. Peterson and Seligman (2004) in their seminal work Character Strengths and Virtues declare "the stance we take toward character is in the spirit of personality psychology and specifically trait theory" (p. 10). In their conception, virtues are core characteristics that are universally valued across cultures (wisdom, courage, humanity, justice, temperance, and transcendence) whereas character strengths (traits) are "the psychological ingredients - processes or mechanisms- that define the virtues" (p.13). Personality psychology defines a trait as an attribute of a person that is relatively long-lasting and stable (Funder 2010). Philosophers use a similar language to define character traits defining them as "relatively longterm stable disposition to act in distinctive ways" (Harman 1999). They key to the definition is that these characteristics, traits, and dispositions are expressed over the long term and are relatively stable across situations (Funder 2010).

Personality psychologists are interested in individual differences between people regarding the relative expression of traits. In this way the studies are often comparative, measuring how much a given trait influences an individual's thought and behavior compared to others who share the same trait. For example, when measured on the Big 5 personality traits (extraversion, agreeableness, conscientiousness, neuroticism, and openness), individuals show high or low levels of each trait 
relative to other people. Each trait is orthogonal, that is, a high or low score on any one trait does not influence the score on the other traits (McCrea \& Costa 1987). Intellectual humility, may, or may not, work in the same way. It may also have orthogonal characteristics relative to other character traits such that, for example, being high in intellectual humility may not impact how high or low a person is in courage, or persistence. However, as with the Big 5, some character traits and virtues may show some kind of correlative relationship. For example, just as people who score low on neuroticism often score high on agreeableness and conscientiousness (Funder 2010), those high in intellectual humility may be high in forgiveness or prudence. It is also possible that intellectual humility may have different characteristics than personality traits, especially in regards to how to measure it or in the relative comparison of the trait between people. Unlike personality traits, it may have a moral standard to which it can be compared (per Miller 2014). We take no position as to if or how character strengths and virtues are distinct from personality traits, our initial interest is simply to understand the unknown (intellectual humility, a virtue with trait-like qualities) by comparison with the known (personality traits).

In this spirit, there may also be correlations between intellectual humility and existing traits related to information seeking, curiosity, and other epistemic pursuits. In this section we highlight them in more detail: the need for cognition, (Cacioppo \& Petty 1982), the need for closure (Kruglanski 1990), those traits from factor models of personality that relate to intellectual humility (The Big 5, HEXACO, and the Big 2), and the role of emotion and cognition.

\section{Need for cognition}

One of the individual differences that lends itself to the kind of open-minded thinking characteristic of intellectual humility is the "need for cognition," which is defined as "a stable individual difference in people's tendency to engage in and enjoy effortful cognitive activity" (Cacioppo et al. 1996, p. 198). People high in need for cognition expend more effort analyzing content and quality of arguments (Haugtvedt, Petty \& Cacioppo 1992), consider arguments central to the issue rather than peripheral features (Petty, Cacioppo \& Goldman 1981), enjoy complex cognitive tasks (Cacioppo \& Petty 1982), and are more attracted to messages that appeal to rational argument than emotion (Haddock et al. 2008). As with any trait, the preferences identified as "need for cognition" exist in people as a matter of degree, some showing low preference for this approach, others a high preference. Those with a high need for cognition use what Petty et al. (1981) call the "central" route of analysis which employs deliberative, rational processes whereas those with a low need for cognition take the "peripheral" route 
which relies on heuristics and attends to surface features (Haugtvedt et al. 1992). It is important to note that those high in need for cognition are more susceptible to context bias demonstrated in mood priming and primacy-recent effects. Cacioppo et al. (1996) aver that this is because those high in need for cognition form stronger initial attitudes compared to those low in need for cognition. When perceived biases are obvious or detectable, however, individuals high in need for cognition are more likely to make the cognitive effort necessary to correct their judgments and consider all the evidence.

Since those high in need for cognition are more curious, open-minded, and enjoy the search for knowledge, it may be one of the important characteristics that makes up intellectual humility (Cacioppo et al. 1996; Stanovich \& West 1997). It reflects an intrinsic motivation for effortful cognition that is more process than results oriented, which can be developed and can change over time (Cacioppo et al. 1996). However, little research has been done on the development of the need for cognition. Although there may be a heritable component, some of the antecedent experiences that would contribute to its development would be those that reinforce a love of learning, experiences of mastery over subjects, a sense of control over one's learning, and experiences of coping with interpersonal problems through reason and verbal competence. Need for cognition is correlated with many important skills for optimal development.

\section{Need for closure}

Another extensively studied motivational characteristic that could have bearing on the psychology of intellectual humility is the need for closure (Kruglanski 1990; Kruglanski et al. 2009; Webster \& Kruglanski 1994). "Closure," in this conception, means the need to make a decision, to have an issue closed. The concept is part of a general framework for the formation of all kinds of knowledge called lay epistemic theory (Kruglanski et al. 2009). This theory has as a fundamental assumption that knowledge is derived from evidence. Evidence can come from all sources, but a special category of evidence in lay epistemic theory comes from the testimony of other people (other people's opinions). Lay epistemic theory has noted individual differences in the process of hypothesis testing and evidence

gathering. Individuals high in need for closure will take in and process less information before making a judgment and give preference to information met early in the decision-making process. Because of the early closure in the epistemic process they also have higher confidence in their judgments than those with a high need to avoid or postpone closure. They tend to be influenced in their judgment of people and their actions by preexisting stereotypes and prejudices, paying less attention to situational or individuating information. People high in need for closure will, for the most part, look to compare 
to those of similar mind and to reject or devalue others who do not share their perspectives and judgments (Kruglanski 1990). These attributes hold for what lay epistemic theory calls "non-specific" closure, which is a need for a firm answer to any question in order to avoid confusion and ambiguity. This need to avoid confusion and ambiguity may lead to a preference to "seize and freeze" early in the judgment process on information that is easily accessible and affords closure. A search for "specific" closure, by contrast means a person is looking for a particular answer to a specific question. A person high in this need (for specific closure) may actually postpone closure until a desirable answer that might bolster self-esteem or be more positive or optimistic can be found (Kruglanski et al. 2009). By closing off the gathering of evidence too early (non-specific closure) or by searching only for evidence that yields a desirable answer (specific closure) those who are high in need for closure are more susceptible to the numerous cognitive biases (such as the availability heuristic or the confirmation bias). Using virtue language, they may be more susceptible to intellectual arrogance (and therefore less intellectually humble).

Lay epistemic theory affords a unique look at the issue of the self-centered nature of heuristics and biases. Heuristics and biases are those mental shortcuts we all make in order to navigate the world in order to not waste precious cognitive resources on processing routine or previously known experiences or simply to reduce our cognitive load in everyday life (Kahneman 2011; Kahneman \& Frederick 2002; Stanovich 1999; Evans \& Stanovich 2013). While both the need for closure and the use of heuristic rules that preference easy to process evidence favor the self as a source of knowledge (i.e. figuring things out for oneself), as opposed to sources external to the self (e.g. relying on other people), the theory introduces another influence on the judgment process: epistemic authority. Kruglanski et al. (2009) define the concept of epistemic authority as "encompassing a combination of perceived expertise and trustworthiness....it addresses the extent to which an individual is prepared to rely on a source's information and to accept it as evidence for the veracity of the source's pronouncements" (p. 175). The key to the function of epistemic authority is in the comparison of the self to another. The decision to rely on the authority of another may depend in part on the perceived gap in epistemic authority between the other and the self. In combination with a need for closure, this could either lead to an over-reliance on the self as epistemic authority (intellectual arrogance) or a denigration of the self as an epistemic authority and an over-reliance on others (gullibility or "group think"). Intellectual humility in the context of lay epistemic theory may lie in a proper balance of a need for closure with an openness to new information and a tolerance for ambiguity, along with a capacity to discern when the self is enough of an epistemic authority or when others need to be sought 
out and relied upon.

\section{Intellectual humility and personality: The Big 5}

Considering intellectual humility within the framework of conceptions of personality such as the FiveFactor Model (The Big Five, McCrae \& Costa 1987, 1997) and the HEXACO (Lee \& Ashton 2004) leads in a promising direction. We can imagine that high levels of the Openness to Experience factor might correlate with high intellectual humility, especially when we look at specific facets of the Openness construct. The facet "openness to ideas," for example, seems to capture an element of curiosity we would expect to find in the intellectually humble; the "values" facet might figure into whether someone is willing to really consider an opposing political or religious view with charity. Similar corollaries of intellectual humility might exist within some facets of Agreeableness, Conscientiousness, and even Emotional Stability.

Along these lines, special attention might be given to the HEXACO model of personality which adds the dimension of Honesty-Humility $(\mathrm{H})$ to the factors mentioned above (Ashton \& Lee 2005). A connection between the $\mathrm{H}$ dimension and socially important criteria such as sincerity, fairness, and modesty has already been demonstrated (Ashton \& Lee 2008). Additionally, the $H$ factor has been negatively correlated with particularly vicious personality traits (e.g.: narcissism, psychopathy, machiavellianism, materialism, and power-seeking) that we would expect to find somewhere opposite of intellectual humility (Ashton \& Lee 2005, 2007): a finding which lends some support to the understanding of intellectual humility as involving a lack of concern for status one's status. Not surprisingly, the $\mathrm{H}$ factor has also been used to show that trait humility is linked to higher social relationship quality (Peters, Rowatt \& Johnson 2011).

Despite these helpful leads in the personality literature, it seems important to avoid oversimplified association of intellectual humility with certain personality traits. Even traits that seem to track with intellectual humility could have their own special hazards. For example, a trait like Openness could easily be an impediment to intellectual virtue if it leads to a kind of non-committal intellectual paralysis. And a person scoring high in Agreeableness might be too compromising, sacrificing intellectual honesty for likability.

As the psychology of intellectual humility is developing, various measures and constructs of intellectual humility are being tested against the Big 5 and the HEXACO in order to assess construct validity. Because of its epistemic dimension, Openness to Experience is often shown to correlate with measures of intellectual humility. Tenelle Porter (2015) tested her measure of intellectual humility with 
two different samples of adults and found significant correlations ranging from .26 to .40 with Openness to Experience. She also found significant correlations in both samples between her measure and Agreeableness and Conscientiousness, and in one sample with Extraversion. Krumrei-Mancuso and Rouse (2016), using a slightly different measure for Openness, also found a robust correlation between their measure of general intellectual humility and Openness (.40). They did not measure other constructs from the Big 5 but did find significant correlations between intellectual humility and general humility, open-mindedness, and tolerance. Price et al (2015) tested their construct of "Open-Minded Cognition," a key component of intellectual humility, and found significant positive correlations with a variety of personality traits including openness to experience, agreeableness, emotional stability (the obverse of neuroticism) and conscientiousness. Leary et al., (2015) also found positive correlations with openness, along with measures of epistemic curiosity, and existential quest.

\section{Intellectual humility and personality: The Big 2}

A recent development in personality and social psychology is a growing discernment of the importance of two main dimensions that are useful in guiding the description of personality traits, how those traits are perceived and judged in individuals, groups, and cultures: namely, agency and communion (Abele \& Wojciszke 2007). Sometimes called the "Big Two" (Abele \& Wojciszke 2013; Bruckmüller \& Abele 2013), they are based on two "fundamental modes of existence" (Bakan 1966) that reflect two intuitive categories of social information processing: perspectives on the self and perspectives of other people. Thus, agency is related to what Able and Wojciszke (2007) call the "goal-pursuit of the self," while communion is related to "consideration of others" (p. 751). Each is identified by their differential focus, that is, agency as individual striving with its dimensions of competence, instrumentality, and power, and communion as social relatedness characterized by warmth, morality, expressiveness, and affiliation (Abele \& Wojciszke 2013). These two categories can also be used as themes to organize the Big 5 traits with agency reflecting the personal growth dimensions of the traits (Extraversion and Intellect) and communion reflecting the socialization dimensions (Agreeableness, Conscientiousness, and Emotional Stability, Digman 1997).

Since agency is characterized by pursuing personal goals and exhibiting skills and accomplishments (traits such as competence, intellectual goodness, or dominance); and communion is related to forming and maintaining social connections (traits such as warmth, morality, social goodness, or nurturance, Bruckmüller \& Abele 2013), intellectual humility, with its epistemic and social dimensions might fall in with either dimension of the Big Two. The intellectual dimension, with its focus on the pursuit of 
truth, might align it more on the agentic side, while the social dimension, with its emphasis on the social skills required for collaborative pursuit of knowledge, might land it more on the communal side (Samuelson et al. 2014).

Gregg, Mahadevan, and Sedikides (2017) used a cross-sectional design to examine patterns of relations that might occur between agency and communion on the one hand, and measures of intellectual arrogance and intellectual humility on the other. They operationalized communion (C) and agency (A) on three different levels: socially, as inclusion (C) and status (A); dispositionally, as warmth (C) and competence (A), and behaviorally, as amiability (C) and assertiveness (A) using self-report scales and items developed in previous research. Intellectual humility and intellectual arrogance were measured by novel instruments developed by the researchers. They found that the higher an individual's communal traits (inclusion, warmth, and amiability) the more that person exhibited aspects of intellectual humility (were more rationally objective) while the opposite was true for those with higher agentic traits (they were less rationally objective). In addition, the higher an individual scored on the measures of agency, the more an individual showed a tendency toward intellectual arrogance (higher BIAS scores). Their conclusion is that high agency and low communion predicts high intellectual arrogance.

\section{\$3: Both Trait and Situation in Intellectual Humility}

We have been discussing intellectual humility as a trait with a certain expectation that, as a trait, it is fairly stable, that is, it will determine a person's behavior in most situations, except for some kind of reasonable response to changing circumstances. This gives us a basis by which we can describe a person as intellectually humble and so, depending on the efficacy of the measure used to determine whether or not any given person has what it takes to be intellectually humble, once we have made such a determination we might also have a basis on which to predict their behavior. We may even be able to correlate intellectual humility with some important life outcomes, especially in the interpersonal realm, like has been done with other traits like the Big 5 (Ozer \& Benet-Martínez 2006).

There is some controversy in the field of social and personality psychology about the power of personality traits to influence behavior. People are not consistent in their behavior across situations (Fleeson, 2004). For example, a person at wedding reception A is observed going from table to table, greeting each guest, laughing, and generally being the life of the party, while that same person, at wedding reception $\mathrm{B}$ is observed sitting alone most of the time, talking only to a handful of people. What is the difference? At wedding A he is the father of the bride and the "host" of the party. At 
wedding $\mathrm{B}$ he is a guest at the wedding of a distant relative and knows hardly anyone. Is this person an introvert or an extrovert? The answer is: it depends. The situation seems to be the determining factor. Or, to return to the example of the caricature of the arrogant philosopher: Does philosophy attract people with intellectual arrogance or do the situations philosophers are routinely in call for the expression of that trait? What is important to study is not how traits make people behave in a certain way, but how people's perceptions of situations and their reactions to them make people behave in a certain way (Fleeson 2004, Funder 2010). We would describe such an approach as "interactionist," which recognizes that situations do have great influence in determining behavior but that the truth is that both come into play. Fleeson (2004) provides an apt description of the interactionist approach:

The same person changes his or her behavior quite rapidly and frequently, presumably in response to changing situation... Although this within-person variance is large and presumably due to individuals adapting to situations, it is possible that individuals adapt such that they nonetheless maintain their relative position compared with others in the same situations. (p. 85)

There have been recent studies that take this interactionist approach to intellectual humility that have yielded fruitful insight. We highlight a few here.

Since the study of intellectual humility is still in its early stages, the first tasks in these investigations is to create measure of traits that are related to intellectual humility and then test them in different situations. Victor Ottati and his colleagues (Price et al. 2015; Ottati et al. 2015) have developed a trait measure for Open Minded Cognition which they describe as a "cognitive style... marked by a willingness to consider a variety of intellectual perspectives, values, attitudes, opinions or beliefs; even those that contradict the individual's prior opinion" (Price et al. 2015, p. 3). They take an interactionist approach, conceiving of Open Minded Cognition as comprised of both trait-like (dispositional) and situational components. Therefore, an individual's average level of open-mindedness across situations would be indicative of "an individual's chronic level of open-mindedness" (p. 5). By the same token, situations may merit increased or decreased levels of open-mindedness, depending on the reaction the situation demands. Price et al. (2015) explore open-minded cognition in three conditions: general open-minded cognition (OMC-G), political open-minded cognition (OMC-P), and religious openminded cognition (OMP-C). They developed a measure to test for each. The six items of the measure are nearly identical. Three assess a person's openness to different or new opinions, arguments, and viewpoints, and three assess a person's resistance or "closedness" to arguments, ideas, or messages, especially those with which they disagree (see chapter 3 for a more detailed discussion of this measure). The difference is the political measure inserts the word "political" before the words argument, ideas, 
opinions, etc., the religious measure the word "religious," while the general measure has no qualifier. (e.g. I try to reserve judgment until I have a chance to hear arguments from both sides of an [political/ religious] issue.)

The evidence for trait expression in different situations in this study comes from the differential correlations of the three measures with other trait measures. For example, the general and political scales show a significant negative correlation with dogmatism, but the religious scale does not, while the religious scale correlates significantly with humility, while the other scales do not. A similar pattern is shown in relation to the Conscientiousness, Neuroticism, and Agreeableness subscales of the Big 5. All three measures correlate with three of the four subscales of Stanovitch and West's (2007) measure of Active Open-Minded Thinking but only the political measure correlates with the "counter-factual thinking" subscale. From these results we see that across individuals, different contexts tap different kinds of characteristics and traits. Moreover, their results show that within individuals, a person can have a high level of Open-Minded Cognition in one area, for example politics, while having a low level in another, like religion.

Ottati and his colleagues (Ottati, Wilson \& Price 2016) further examined the interaction of disposition and situation in Open-Minded Cognition. They constructed a model, called the Flexible Merit Standard Model, that can account for both disposition and situation in the expression of OpenMinded Cognition. They surmised that in any given situation, a person determines how much OpenMinded Cognition is merited, that is, across situations the standard by which one should be openminded is flexible. That determination, of course, is influenced by how chronically open-minded that person is across situations. Therefore, the Flexible Merit Standard Model accounts for a trait $\mathrm{x}$ situation interaction in the expression of Open-Minded Cognition. From the results of this study they report:

Clearly, both dispositional and situational forces are at play when individuals adopt a particular level of Open-Mindedness in a specific situation. In many situations, the dispositional and situational forces function as separate and independent sources of norm activation that produce additive effects (Additive Postulate). In some situations, however, individuals high in dispositional Open-Mindedness may be more responsive to the situation than individuals low in dispositional OpenMindedness (Discerning Open-Mindedness Postulate). (p. 30).

Ottati et al. (2015), call this the "Joint Influence Hypothesis" and it confirms what Fleeson (2004) and others have asserted that neither dispositional tendencies or situation forces are adequate in explaining a person's behavior at any given time, but it is the interaction of the two in specific contexts that will determine how a person acts and reacts. This is an especially important insight for intellectual humility. 
As Price et al. (2015) show, there are differences even with a person depending on whether the situation is politics or religion. Knowing how important the interaction of situation and personality to human encounters could help us develop more civil ways of discourse, especially in politics and religion.

Mark Leary, Rick Hoyle and their colleagues (Leary et al. 2015; Hoyle et al. 2016) took a similar interactionist approach to their study of intellectual humility. First, they devised and tested a general measure of intellectual humility (Leary et al. 2015) and tested it in a variety of situations. They wondered how intellectual humble people would be in a situation of disagreement (e.g. religion and politics). In one of their studies (Leary et al. 2015), they sorted the participants into two groups, those scoring low on their general intellectual humility scale and those who scored high. They then determined how religious individuals were within those two groups. Finally, participants were randomly assigned to read one of three essays on the effects of religion on individuals and society, one pro-religious, one anti-religious, and one offering a balanced view. Participants then rated how much they agreed with the essay, the accuracy of the beliefs of the writer, the impression they had of the writer on a number of personal qualities (e.g. warm or cold, moral or immoral), how they felt while reading the essay, and finally, answered a question on religion's effect on society on a positive to negative scale and how certain they were about their own personal religious views. They found that the higher people scored in the intellectual humility measure, the less they were certain of their views and the less they thought their views were superior to others. Moreover, though the majority of participants disagreed with the anti-religious essay, only those high in intellectual humility were more open to it. They preferred the balanced view and not those that were one-sided. The other situation they examined was people's reaction to politicians who change their minds. Those high in intellectual humility were more willing to vote for a candidate who changed positions on an issue, than those who where low in intellectual humility.

Hoyle et al. (2015) hypothesized that people will be less intellectually humble the more specific the issue. Thus, while a person might be intellectually humble about politics in general, they may not be as intellectually humble about gun control, and may show even less intellectual humility about background checks for gun purchases. They found was that while there was a modest overlap between a person's scores on the general intellectual humility measure and the measures of specific intellectual humility, and the correlation did not necessarily weaken as the issues became more specific. However, what they did find was that the more extreme a person's view on a specific issue (the more the strongly agreed or disagreed with an issue such as "physician-assisted suicide should be legal in all states" for 
example), the lower their specific intellectual humility. They also found that the method by which people came to their views had an impact on specific intellectual humility. Those whose opinions were formed by their own exploration and study were less intellectually humble than those who formed opinions by other means (e.g. from experts, anecdotal evidence, non-experts, "gut feelings," common knowledge, common sense, religious teachings, emotions, or evaluating facts and reasoning carefully).

\section{\$5: Conclusion}

In this chapter we have explored the situational and dispositional determinants of intellectual humility. We began first by positioning the study of intellectual humility in the tradition of personality psychology and examining those qualities of intellectual humility that appear relatively long-lasting and stable, therefore making intellectual humility look much like a personality trait. We proposed that because intellectual humility is a complex phenomenon with many facets, it is likely composed of many traits and attributes already measured in social and personality psychology such as some of the Big 5 (Openness to Experience, Agreeableness, Conscientiousness, and even Emotional Stability, McCrae \& Costa 1987, 1997) as well as the Big 2 (agency and communion, Abele \& Wojciszke 2007). We looked also at epistemic traits such as need for cognition (Cacioppo et al. 1996) and the need for closure (Kruglanski 1990). Scholars have begun to define and measure intellectual humility (e.g. Porter 2015; Krumrei-Mancuso \& Rouse 2016; Leary et al. 2015)) and related traits (Open-Minded Cognition, Price et al. 2015) to examine its stability and expression across time and situations.

It has become clear that intellectual humility is also influenced by situations. We have seen an interactionist approach to the study of intellectual humility, measuring its expression in general and in specific situations (Ottati et al. 2015; Price et al. 2015; Hoyle et al. 2015; Leary et al. 2015). Ideas like the "Joint Influence Hypothesis" (Ottati et al. 2015) and studies that show differences in the expression of intellectual humility depending on the subject matter (Hoyle et al. 2015; Leary et al. 2015), demonstrate that no simple trait measure will suffice in determining how intellectually humble a person might be in any given situation.

So what are we to conclude? Is intellectual humility a stable and long-lasting trait or blown about by the winds of the situation? The answer is: it is both. About the trait vs. situation debate, Fleeson (2004) concludes:

There is no longer any need for debate because large within-person variability and the sensitivity of behavior to situations are not a threat to the viability of traits, and the power of traits is not a threat to the need to explain the considerable amount of 
within-person behavioral variability. It is time for the study of personality to go forward with both approaches (p. 86).

We believe this holds true for intellectual humility as well. Measures that assess the relative disposition of intellectual humility in people are necessary to understanding this important intellectual virtue. Examining the situations that either promote or inhibit the expression of intellectual humility is also a critical line of investigation. Testing the trait of intellectual humility in various situations will yield critical knowledge of how intellectual humility plays out. The later line of research - the trait x situation interaction - may be most informative in promoting conditions for more civil discourse, especially in areas of disagreement. Learning how to exchange ideas in an intellectually humble way, and the situations which might promote such exchange, would make a positive impact on the field of philosophy in particular, and on our society in general.

\section{References:}

Abele, A. E. and Wojciszke, B. (2007). Agency and communion from the perspective of self versus others. Journal of Personality and Social Psychology, 93(5), pp. 751-763. doi:10.1037/00223514.93.5.751

Abele, A. E. and Wojciszke, B. (2013). The Big Two in Social Judgment and Behavior. Social Psychology, 44(2), pp. 61-62. doi:10.1027/1864-9335/a000137

Ashton, M. C. and Lee, K. (2005). Honesty-Humility, the Big Five, and the Five-Factor Model. Journal of Personality, 73(5), pp. 1321-1353. doi: 10.1111/j.1467-6494.2005.00351.x

Ashton, M. C. and Lee, K. (2007). Empirical, theoretical, and practical advantages of the HEXACO model of personality structure. Personality and Social Psychology Review, 11(2), pp. 150-166. doi: $10.1177 / 1088868306294907$

Ashton, M. C. and Lee, K. (2008). The HEXACO model of personality structure and the importance of the $\mathrm{H}$ factor. Social and Personality Psychology Compass, 2(5), pp. 1952-1962. doi: 10.1111/j.1751-9004.2008.00134.x

Bakan, D. (1966). The duality of human existence. An essay on psychology and religion. Chicago: Rand McNally. Bruckmüller, S. and Abele, A. E. (2013). The density of the Big Two: How are agency and communion structurally represented?. Social Psychology, 44(2), pp. 63-74. doi:10.1027/1864-9335/a000145 
Cacioppo, J. T. and Petty, R. E. (1982). The need for cognition. Journal of Personality and Social Psychology, 42(1), pp. 116-131. doi: 10.1037/0022-3514.42.1.116

Cacioppo, J. T., Petty, R. E., Feinstein, J. A. and Jarvis, W. B. G. (1996). Dispositional differences in cognitive motivation: The life and times of individuals varying in need for cognition. Psychological Bulletin, 119(2), pp. 197-253. doi: 10.1037/0033-2909.119.2.197

Church, I.M. (2017). The Limitations of the Limitations-Owning Account of Intellectual Humility. Philosophia, 45(3), pp. 1-8.

Church, I.M. (2016). The Doxastic Account of Intellectual Humility. Logos \& Episteme, 7, pp. 413433. https://doi.org/10.5840/logos-episteme20167441

Church, I.M. and Barrett, J.L. (2017). Intellectual Humility. In: E.L. Worthington Jr., D.E. Davis, and J.N. Hook. eds,. The Routledge Handbook of Humility. New York: Routledge, pp. 62-75.

Church, I.M. and Samuelson, P.L. (2017). Intellectual Humility: An Introduction to the Philosopby and Science. New York: Bloomsbury Academic.

Davis, D. E., Hook, J. N., Worthington, E. L., Van Tongeren, D. R., Gartner, A. L., Jennings, D. J. and Emmons, R. A. (2011). Relational Humility: Conceptualizing and Measuring Humility as a Personality Judgment. Journal of Personality Assessment, 93(3), pp. 225-234. doi: 10.1080/00223891.2011.558871

Davis, M. H. (1983). Measuring individual differences in empathy: Evidence for a multidimensional approach. Social Psychology, 44, pp. 113-126.

Digman, J. M. (1997). Higher-order factors of the Big Five. Journal Of Personality And Social Psychology, 73(6), pp. 1246-1256. doi:10.1037/0022-3514.73.6.1246

Evans, J. T. \& Stanovich, K. E. (2013). Dual-process theories of higher cognition: Advancing the debate. Perspectives On Psychological Science, 8(3), pp. 223-241.

Fleeson, W. (2004). Moving personality beyond the person-situation debate: The challenge and the opportunity of within-person variability. Current Directions in Psychological Science, 13(2), pp. 8387. doi: 10.1111/j.0963-7214.2004.00280.x

Funder, D. C. (2010). The Personality Puzzle. $5^{\text {th }}$ ed. New York: W. W. Norton and Co.

Gregg, A. P., Mahadevan, N. and Sedikides, C. (2017). Intellectual arrogance and intellectual humility: correlational evidence for an evolutionary-embodied-epistemological account. The Journal of Positive Psychology, 12:1, pp. 59-73. DOI: 10.1080/17439760.2016.1167942 
Haddock, G., Maio, G. R., Arnold, K. and Huskinson, T. (2008). Should persuasion be affective or cognitive? The moderating effects of need for affect and need for cognition. Personality and Social Psychology Bulletin, 34(6), pp. 769-778. doi: 10.1177/0146167208314871

Harman, G. (1999). Moral philosophy meets social psychology: Virtue ethics and the fundamental attribution error. Proceedings of the Aristotelian Society 99. pp. 315-331. Retrieved online at http://www.filosofia.unimi.it/ zucchi/NuoviFile/harman.pdf

Hoyle, R. H., Davisson, E. K., Diebels, K. J. and Leary, M. L. (2016). Holding specific views with humility: Conceptualization and measurement of specific intellectual humility. Personality and Individual Differences 97, pp. 165-172.

Kahneman, D. (2011). Thinking, fast and slow. New York: Farrar, Straus and Giroux.

Kahneman, D. \& Frederick, S. (2002). Representativeness revisited: Attribute substitution in intuitive judgment. In: T. Gilovich, D. Griffin and D. Kahneman. eds., Heuristics and biases: The psychology of intuitive judgment. New York: Cambridge University Press, pp. 49-81.

Kruglanski, A. W. (1990). Lay epistemic theory in social-cognitive psychology. Psychological Inquiry, 1(3), pp. 181-197. doi: 10.1207/s15327965pli0103_1

Kruglanski, A. W., Dechesne, M., Orehek, E. and Pierro, A. (2009). Three decades of lay epistemics: The why, how, and who of knowledge formation. European Review of Social Psychology, 20(1), pp. 146-191. doi: 10.1080/10463280902860037

Krumrei-Mancuso, E. J. and and Rouse, S. V. (2016). The development and validation of the Comprehensive Intellectual Humility Scale. Journal of Personality Assessment. 98 (2), pp. 209-21. doi:10.1080/00223891.2015.1068174

Landrum, R. E. (2011). Measuring dispositional humility: A first approximation. Psychological Reports, 108(1), pp. 217-228. doi: 10.2466/02.07.09.pr0.108.1.217-228

Leary, M. R., Diebels, K. J., Davisson, E. K., Isherwood, J. C., Jongman-Sereno, K. P., Raimi, K. T., Deffler, S. A. and Hoyle, R. A. (2015). Cognitive and interpersonal features of intellectual humility. Personality and Social Psychology Bulletin, 43 (6), pp. 793-813. doi:10.1177/0146167217697695

Lee, K. and Ashton, M. C. (2004). Psychometric properties of the HEXACO personality inventory. Multivariate Behavioral Research, 39(2), pp. 329-358. doi: 10.1207/s15327906mbr3902_8

McCrae, R. R. and Costa, P. T. (1987). Validation of the five-factor model of personality across instruments and observers. Journal of Personality and Social Psychology, 52(1), pp. 81-90. doi: 10.1037/0022-3514.52.1.81 
McCrae, R. R. and Costa, P. T., Jr. (1997). Personality trait structure as a human universal. American Psychologist, 52(5), pp. 509-516. doi: 10.1037/0003-066x.52.5.509

Miller, C.B. (2014). Character and Moral Psychology. New York: Oxford University Press.

Price, E.D., Ottati, V., Wilson, C. and Kim, S. (2015). Open-minded cognition. Personality and Social Psychology Bulletin, 41(11), pp. 1488-1504.

Ottati, V., Wilson, C., Price, E.D. and Sumaktoyo, N. (2015). When self-perceptions of expertise increase closed-minded cognition: The earned dogmatism effect. Journal of Experimental Social Psychology, 61, pp. 131-138.

Ottati, V., Wilson, C., Price and E.D. (2016). Open Minded Cognition in Social Context. Unpublished manuscript.

Ozer, D. J. and Benet-Martínez, V. (2006). Personality and the prediction of consequential outcomes. Annual Review Of Psychology, 57, pp. 401-421. doi:10.1146/annurev.psych.57.102904.190127

Peters, A., Rowatt, W., C. and Johnson, M. K. (2011). Associations between dispositional humility and social relationship quality. Psychology, 2(3), pp. 155-161. doi: 10.4236/psych.2011.23025.

Peterson, C. and Seligman, M. E. P. (2004). Character strengths and virtues: A handbook and classification. Washington, DC: American Psychological Association, Oxford University Press.

Petty, R. E., Cacioppo, J. T. and Goldman, R. (1981). Personal involvement as a determinant of argument-based persuasion. Journal of Personality and Social Psychology, 41(5), pp. 847-855. doi: 10.1037/0022-3514.41.5.847

Porter, T. (2015). Intellectual humility, mindset, and learning. Unpublished dissertation, Stanford University, Palo Alto, CA.

Price, E.D., Ottati, V., Wilson, C. and Kim, S. (2015). Open-minded cognition. Personality and Social Psychology Bulletin, 41(11), pp. 1488-1504.

Rowatt, W. C., Powers, C., Targhetta, V., Comer, J., Kennedy, S. and Labouff, J. (2006). Development and initial validation of an implicit measure of humility relative to arrogance. The Journal of Positive Psychology, 1(4), pp. 198-211. doi: 10.1080/17439760600885671

Samuelson, Peter L. and Ian M. Church. (2014). When Cognition Turns Vicious: Heuristics and Biases in Light of Virtue Epistemology. Philosophical Psychology, 28:8, pp. 1095-1113. doi: $10.1080 / 09515089.2014 .904197$

Samuelson, P. L. Jarvinen, M. and Paulus, T. B., Reid, A., Church, I. M. and Barrett, J. (2015). Must we trust to be humble?: Character assessment and epistemic trust in children. Paper presented 
at the Intellectual Humility: Scientific, Philosophical, \& Theological Perspectives Conference, Catalina, Is. CA.

Samuelson, P. L., Jarvinen, M., Paulus, T. B., Church, I. M., Hardy, S. A. and Barrett, J. (2015). "Implicit Theories of Intellectual Virtues and Vices: A Focus on Intellectual Humility." Journal of Positive Psychology, 10:5, pp. 389-406. doi: 10.1080/17439760.2014.967802

Stanovich, K. E. (1999). Who is rational?: Studies of individual differences in reasoning. Mahwah, NJ: Lawrence Erlbaum Associates Publishers.

Stanovich, K. E. and West, R. F. (1997). Reasoning independently of prior belief and individual differences in actively open-minded thinking. Journal of Educational Psychology, 89(2), pp. 342357. doi: 10.1037/0022-0663.89.2.342

Tangney, J. P. (2000). Humility: Theoretical perspectives, empirical findings and directions for future research. Journal of Social and Clinical Psychology, 19(1), pp. 70-82. doi: 10.1521/jscp.2000.19.1.70

Webster, D. M. and Kruglanski, A. W. (1994). Individual differences in need for cognitive closure. Journal of Personality and Social Psychology, 67(6), pp. 1049-1062. doi: 10.1037/00223514.67.6.1049 